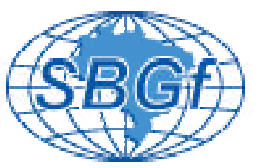

\title{
LabSis: Um Ambiente para Desenvolvimento de Aplicações Sísmicas em Matlab
}

Cristiano da Silva Marcolino (Cepetro/Unicamp \& Schlumberger), Martin Tygel (IMEC/Unicamp), Rodrigo Portugal (DGRN/Unicamp)

Copyright 2004, SBGf - Sociedade Brasileira de Geofísica

Este texto foi preparado para a apresentação no I Simpósio de Geofísica da Sociedade Brasileira de Geofísica, São Paulo, 26-28 de setembro de 2004. Seu conteúdo foi revisado pela Comissão Tecno-científica do I SR-SBGf mas não necessariamente representa a opinião da SBGf ou de seus associados. E proibida a reprodução total ou parcial deste material para propósitos comerciais sem prévia autorização da SBGt.

\section{Resumo}

Em trabalhos realizados por pesquisadores do Laboratório de Geofísica Computacional e do Depto. de Geologia e Recursos Naturais da Universidade Estadual de Campinas (Unicamp), foram desenvolvidas várias funções em Matlab, destinadas ao processamento, modelagem e imageamento de dados sísmicos. De forma descentralizada, cada função cumpre o papel de resolver um determinado problema específico, fazendo com que a intercomunicação entre tais funções seja prejudicada por uma falta de padronização, com relação à formatação de dados e entrada e saída de parâmetros. Visando suprir essa deficiência, foi desenvolvida a plataforma LabSis, que cumpre um papel integrador das várias funções isoladas, agregando facilidade ao seu uso. Através de um ambiente gráfico baseado em janelas, a plataforma Labsis é escrita em Matlab, aumentando o potencial de uso perante a comunidade de pesquisa em geofísica, com ênfase em processamento sísmico.

\section{Introdução}

Para integrar as diferentes funções existentes, provenientes de diferentes autores, dos diversos departamentos que trabalham com sísmica na Unicamp, - LabSis é constituído de funções "casca", que realizam o elo entre as funções originais e o usuário. O Labsis foi escrito na linguagem original destas funções já existentes (Matlab), já que um dos objetivos do trabalho era não alterar o código destas funções para manter o trabalho dos autores.

Construído para ser um pacote que englobe funções presentes e futuras, o LabSis atualmente pode modelar dados sísmicos utilizando algoritmos que fazem o uso de traçado de raios, aproximação de Born e integral de Kirchhoff. O LabSis pode também, fazer análise de velocidades NMO, transformada Tau-p e análise AVO, além de migração Kirchhoff em profundidade e demigração Kirchhoff. $O$ dado pode ser a qualquer momento visualizado. Isso é feito através de uma ferramenta para plotagem de dados sísmicos. $O$ programa permite ao usuário trabalhar com vários dados sísmicos ao mesmo tempo, sendo possível alternar entre eles a qualquer momento. O programa é totalmente gráfico, liberando o usuário de recorrer a linhas de comando. No entanto, essa opção existe para os casos em que se torne necessária. O LabSis é integrado com o InterSis, um software desenvolvido também no
Laboratório de Geofísica Computacional da Unicamp, e que utiliza a biblioteca gráfica GTK+ e é usado para modelagem sísmica pela teoria dos raios e por diferenças finitas. Desta forma, é possível gerar um modelo geológico complexo no InterSis e exportá-lo para o LabSis para a modelagem sísmica. Alternativamente, é possível fazer a modelagem sísmica no InterSis e ler este dado no LabSis, para ser processado ou imageado. A importação de dados Seismic Unix (SU) e SEG-Y, faz com que o LabSis possa se comunicar com o mundo externo, permitindo a utilização de dados gerados por outros softwares. O LabSis é um software didático desenvolvido especificamente para o ensino e a pesquisa, tornando possível entender, na prática, os conceitos teóricos expostos em sala de aula. O software é ideal para ser utilizado em cursos de graduação e pósgraduação. Por ser um programa leve, não exige uma máquina robusta, a não ser que o dado utilizado assim o exija. Por ser um pacote integrado e completo, as chances de distribuição são maiores do que as das funções separadas, atingindo uma gama maior de usuários e permitindo assim uma melhor divulgação dos programas do pacote.

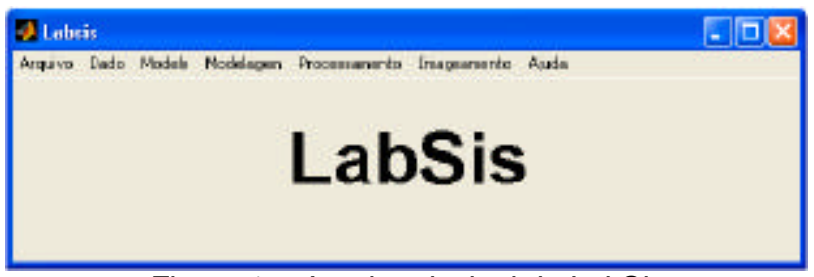

Figura 1 - Janela principal do LabSis.

\section{Características do Programa}

A principal característica do LabSis, é o fato de ser um pacote integrador de várias funções diferentes. Para facilitar tal tarefa, o principal recurso deste programa é poder fazer isso sem a necessidade de usar a linha de comandos, usando uma linguagem orientada a objetos, totalmente visual. Isto permite o uso do software de maneira intuitiva e versátil. O LabSis é um software multivariável, isto é, ele pode trabalhar com vários dados sísmicos ao mesmo tempo. Essa característica dá ao usuário uma mobilidade maior para trabalhar com modelagem, processamento e imageamento, sem a necessidade de sair e entrar no programa, ou ainda limpar a memória para trabalhar com um novo dado. Desta forma, há a possibilidade de reprocessamento do dado por diferentes algoritmos, mantendo o dado original na memória para comparação.

O fato de o LabSis ter sido escrito em Matlab, o torna multi-plataforma pois, o Matlab é suportado em Microsoft Windows e sistemas Unix. O LabSis foi devidamente testado em MS Windows e em GNU Linux, tendo obtido igual funcionalidade e performance em ambas as 
plataformas. O LabSis permite a criação de dados sísmicos, utilizando vários arranjos diferentes, sendo que as possíveis limitações residem apenas nas funções externas utilizadas. No presente estágio, o LabSis permite ao usuário trabalhar com as seguintes configurações: CO (afastamento comum), CMP (ponto médio comum), CS (fonte comum) e ZO (afastamento nulo).

Todas funções do LabSis com funcionalidades semelhantes são agrupadas por módulos. Esses módulos podem ser acessados através de uma hierarquia de menus e submenus que ficam na barra de ferramentas da janela principal, assim como a maioria dos programas com interface visual. Esses menus estão agrupados através dos seguintes módulos: Dado, Modelo, Modelagem, Processamento e Imageamento.

A criação de um novo dado sísmico a ser modelado é feita através de uma interface interativa (como visto na Figura 2), onde o usuário entra com todos os parâmetros necessários à modelagem, tais como: tipo de configuração, geometria, posição das fontes e dos receptores, tempo total de amostragem, intervalo de amostragem, tipo de pulso de entrada, etc. Após todos os parâmetros serem escolhidos e o modelo geológico construído, o usuário pode escolher um algoritmo para a modelagem sísmica. Todos esses parâmetros podem ser posteriormente editados, através das ferramentas de edição apropriadas encontradas no LabSis.

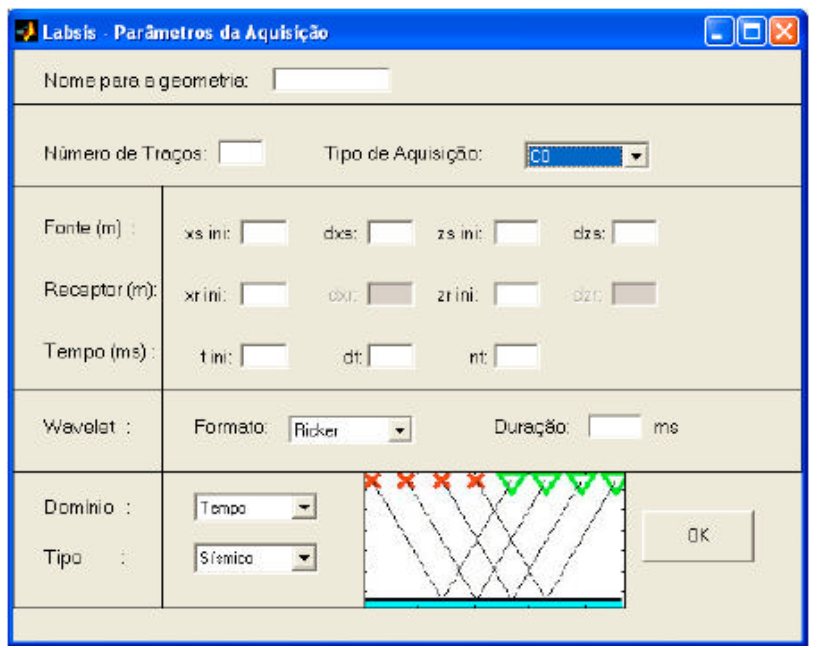

Figura 2 - Tela para a entrada dos parâmetros necessários para a modelagem de dados sísmicos.

\section{Exemplos}

Para a modelagem sísmica numérica é possível atualmente no LabSis usar algoritmos de traçado de raios, aproximação de Born e Integral Kirchhoff. Na Figura 3 (à esquerda)., tem-se um modelo geológico em forma de talude, onde a velocidade da camada 1 é de $2500 \mathrm{~m} / \mathrm{s}$, e a velocidade abaixo do refletor é de $3000 \mathrm{~m} / \mathrm{s}$. O modelo é coberto por uma configuração sísmica de afastamento comum (CO) com 60 pares fonte-receptor e um afastamento de $25 \mathrm{~m}$ Todos os parâmetros do modelo e da aquisição, foram gerados no LabSis. À direita da
Figura 3, tem-se o dado modelado no LabSis utilizandose o algoritmo de traçado de raios. Esse dado foi plotado usando-se a ferramenta do LabSis para visualização de dados sísmicos.

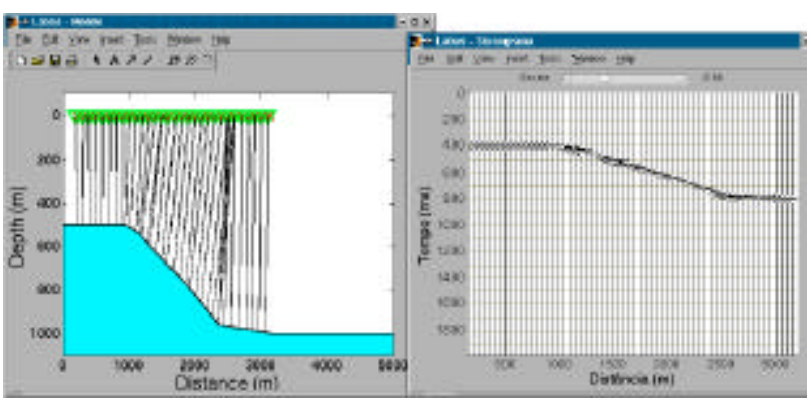

Figura 3 - Modelo em forma de talude com arranjo de afastamento comum (esq.) e o dado modelado por traçado de raios (dir.).

Para o imageamento, o LabSis dispõe de duas ferramentas: migração Kirchhoff em profundidade, e demigração Kirchhoff. A migração Kirchhoff está baseada no empilhamento de dados no domínio do tempo através de curvas de difração construídas em cada ponto de uma malha em profundidade. A demigração é o processo inverso à migração. Na Figura 4 , tem-se à esquerda o dado da Figura 3 migrado em profundidade através do algoritmo do LabSis de migração Kirchhoff, sendo que à direita é apresentado o dado demigrado, obtido através da utilização do algoritmo do LabSis de demigração Kirchhoff a partir do dado migrado ao lado.

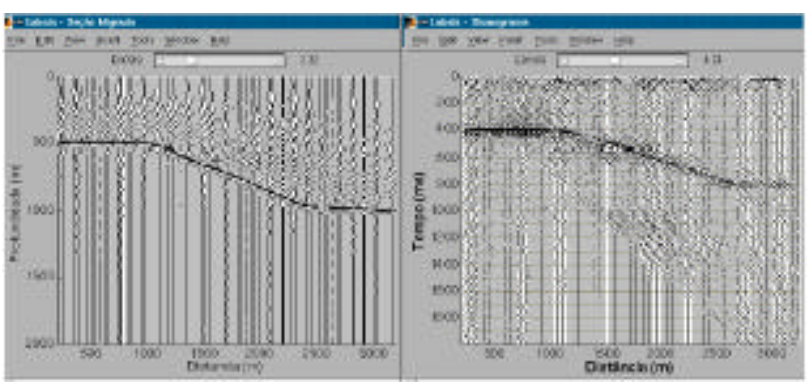

Figura 4 - Dado sísmico migrado a partir do dado da figura 3 (esq.) e dado sísmico demigrado a partir do dado migrado à esquerda (dir.).

Para o processamento sísmico, o LabSis conta com ferramentas para análise AVO, análise de velocidades NMO, e transformada Tau-P. Para um exemplo de análise de velocidades $\mathrm{NMO}$, modelou-se no LabSis um dado sísmico CMP a partir de um modelo geológico de quatro camadas planas horizontais. A partir deste dado, pode-se fazer uma análise NMO, como visto na Figura 5. Nesta figura, tem-se à esquerda o dado sísmico, e à direita, se encontra a correção NMO usando a velocidade de $1600 \mathrm{~m} / \mathrm{s}$, que corresponde à velocidade correta para a primeira camada (em vermelho). O dado sísmico pode também ser analisado em um painel $\mathrm{NMO}$, onde o usuário pode entrar com: velocidade inicial, velocidade final e incremento para as velocidades. Desta forma, 
pode-se construir um painel com as correções NMO para cada velocidade, como visto na Figura 6 . O número de painéis foi limitado em três para não aumentar o tamanho da figura.
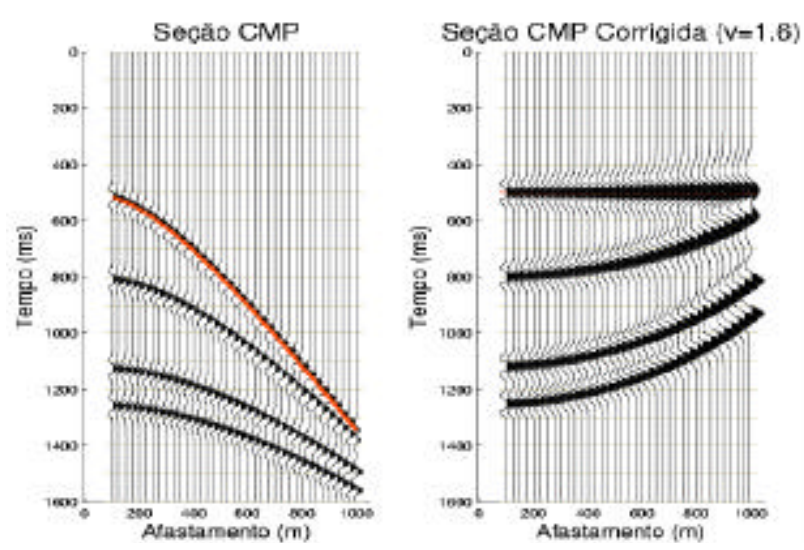

Figura 5 - Dado de reflexão sísmica (esq) e sua correção NMO (dir.).

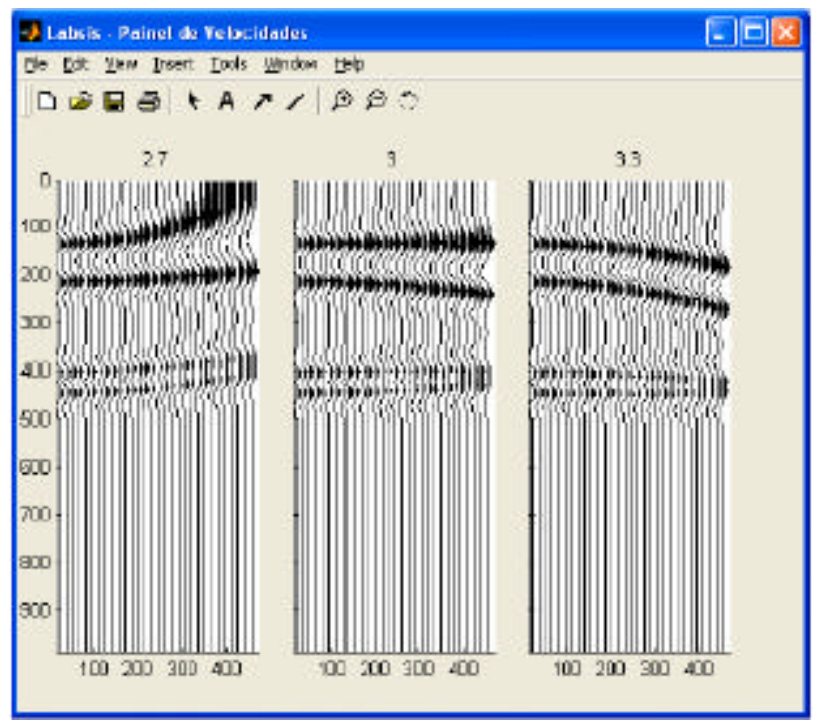

Figura 6 - Painel com correções NMO gerado pelo LabSis, neste exemplo foram usadas apenas três velocidades para reduzir o tamanho da figura.

Para a transformada Tau-P, construiu-se um modelo de 4 camadas planas com espessuras de $150 \mathrm{~m}, 200 \mathrm{~m}, 150 \mathrm{~m}$ e $200 \mathrm{~m}$ e velocidades de $2500 \mathrm{~m} / \mathrm{s}, 300 \mathrm{~m} / \mathrm{s}, 2700 \mathrm{~m} / \mathrm{s}$ e $3500 \mathrm{~m} / \mathrm{s}$ respectivamente. O dado foi modelado como um arranjo de ponto de tiro comum, com 80 receptores com um espaçamento de $20 \mathrm{~m}$ e com a fonte no centro do arranjo. Os dados foram modelados no LabSis usando-se um agorítmo de traçado de raios. O resultado desta modelagem se encontra na Figura 7 (à esquerda). A transformada para o domínio Tau-p se encontra à direita na mesma figura.

\section{Discussão e Conclusões}

Neste trabalho, foi apresentado o pacote LabSis, para tratamento de dados sísmicos, usando a interface gráfica do Matlab. O LabSis integra várias funções de programadores distintos, permitindo a comunicação entre elas, sem que o usuário se dê conta de que está usando funções diferentes. A existência destas funções que trabalhavam separadamente, foi a principal motivação que levou à criação do LabSis. O programa conseguiu atingir seus objetivos com uma interface clara e intuitiva.

Além das funções existentes no programa, pode-se facilmente introduzir novas funções, permitindo que o LabSis possa crescer em conteúdo. A intenção deste trabalho, é que ele tenha continuidade e que, a cada vez que uma nova função for criada para resolver um determinado problema, ela possa ser incorporada ao programa, para que possa ser compartilhada com outros usuários, permitindo assim o aproveitamento máximo da nova contribuição.

\section{Agradecimentos}

Esse trabalho não seria possível sem o financiamento do Cepetro - Centro de Estudos de Petróleo/ Unicamp e o apoio da Schlumberger.

\section{Referências}

Cervený, V., 2001, Seismic ray theory: Cambridge University Press.

Gajewski, D., and C., V., 2002, Revisiting NMO Again?: EAGE 64th Conference \& Technical Exhibition - Florence, Italy.

Hubral, P., Schleicher, J., and Tygel, M., 1996, A Unified Approach to 3-D Seismic Reflection Imaging, part 1: Basic concepts: Geophysics, , no. 61, 742-758.

Jaramillo, H., and Bleistein, N., 1999, The Link of Kirchhoff Migration and Demigration to Kirchoff and Born Modeling. Geophysics, 64, no. 6, 1793-1805.

Marcolino, C., 2004. LabSis: Uma Interface para Desenvolvimento de Aplicações Sísmicas em Matlab. Tese de Mestrado. Faculdade de Engenharia Mecânica / Instituto de Geociencias - Unicamp.

Ochoa, A., 2003, Intersis: Uma Interface Gráfica para Modelamento Sísmico. Tese de Mestrado.s, Universidade de Campinas.

Tygel, M., Schleicher, J., and Hubral, P., 1996, A Unified Approach to 3-D Seismic Reflection Imaging, part 2: Theory: Geophysics, no. 61, 759-775.

Tygel, M., Santos, L., Schleicher, J., and Hubral, P., 1999a, Kirchhoff Imaging as a Tool for AVO/AVA Analysis: The Leading Edge, 18, no. 8, 940-945. 


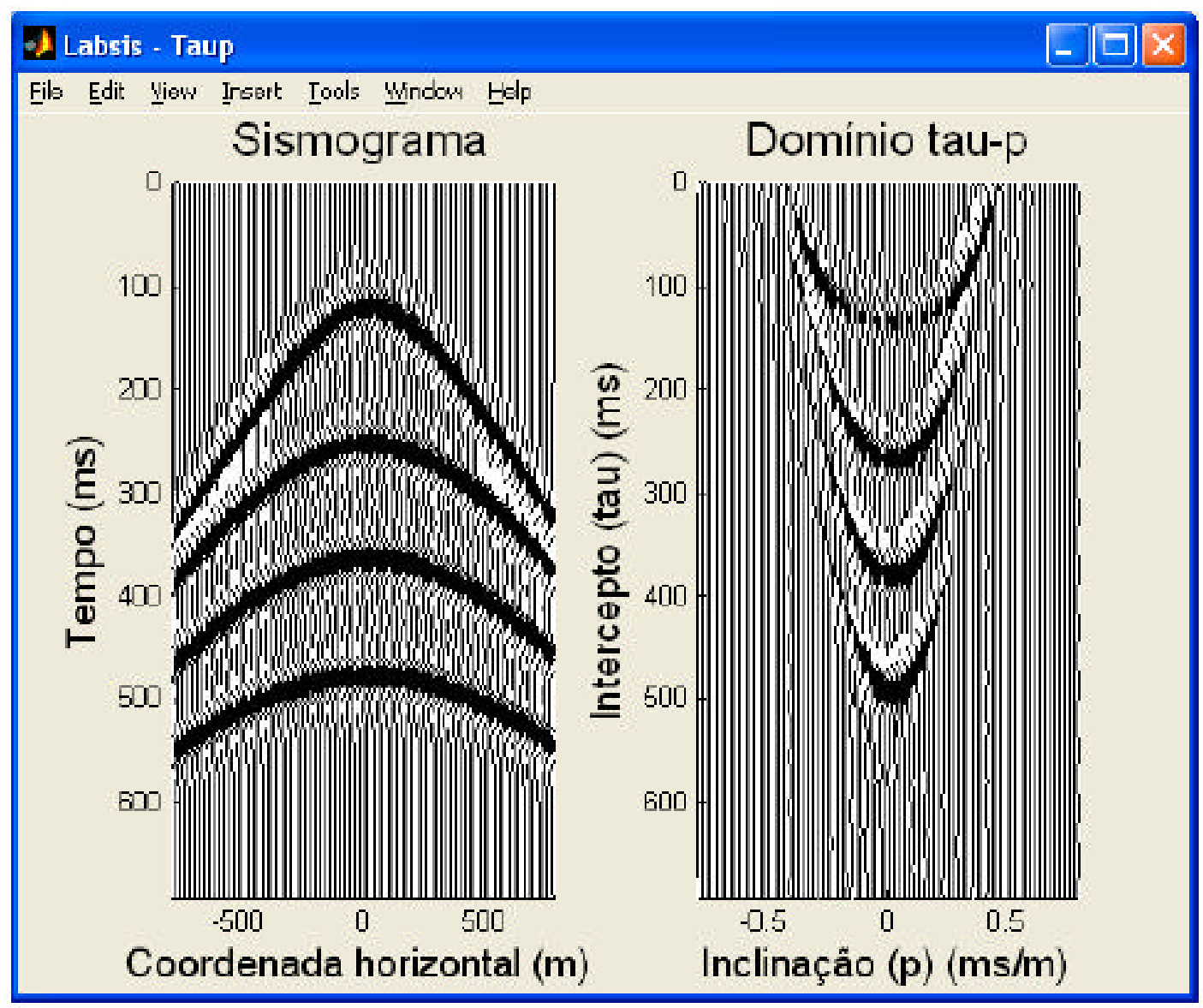

Figura 7 - Dado sísmico de arranjo de tiro comum (CS) para um modelo geológico de quatro camadas planas horizontais (esq.) e sua transformada para o domínio Tau-P (dir.). 